\title{
Evidence that upregulation of serum IGF-1 concentration can trigger acceleration of diabetic retinopathy
}

\author{
E Chantelau
}

\begin{abstract}
Background-Acute reduction of chronic hyperglycaemia can accelerate early diabetic retinopathy. In adolescent patients with Mauriac's syndrome, this phenomenon is related to an upregulation of subnormal serum IGF-1 levels.

Aim-To obtain longitudinal data on serum IGF-1 and retinopathy status in poorly controlled adult insulin dependent (type 1) diabetic patients without Mauriac's syndrome, in whom hyperglycaemia is reduced by intensive insulin therapy.

Methods-Four patients with chronic severe insulin deficiency and early microangiopathy were studied prospectively. Changes in plasma glucose, $\mathbf{H b A}_{1 \mathrm{c}}$, serum IGF-1 levels, proteinuria, retinopathy, and clinical status were followed up closely. Results-Reducing hyperglycaemia from $>16 \mathrm{mmol} / \mathrm{l}$ (equivalent to $\mathrm{HbA}_{\mathrm{ic}}>11 \%$ ) to $<10 \mathrm{mmol} / 1\left(\mathrm{HbA}_{1 \mathrm{c}}<8 \%\right)$ within 5 months increased serum IGF-1 levels by $70-220 \%$. While proteinuria and symptomatic neuropathy regressed, retinopathy progressed from the mild to the severe nonproliferative stage with maculopathy $(n=4)$, and to the proliferative stage $(n=1)$. Laser coagulation was commenced upon the appearance of sight threatening macular oedema $(n=4)$.

Conclusion-Upregulation of serum IGF-1 preceding retinal deterioration in these patients suggests a cause-effect relation, consistent with earlier experimental and clinical data.

(Br f Ophthalmol 1998;82:725-730)
\end{abstract}

Animal experiments have shown that intravitreal injection of insulin-like growth factor 1

\section{Accepted for publication} 22 January 1998

after improving diabetes control)

\begin{tabular}{llllllll} 
Table 1 & \multicolumn{7}{l}{ Patient data (beforelafter improving diabetes control) } \\
\hline Patient & $\begin{array}{l}\text { Sex/age } \\
\text { (years) }\end{array}$ & $\begin{array}{l}\text { Height } \\
(\mathrm{cm})\end{array}$ & $\begin{array}{l}\text { Weight } \\
(\mathrm{kg})\end{array}$ & $\begin{array}{l}\text { Proteinuria } \\
(\mathrm{mg} / \mathrm{l})\end{array}$ & $\begin{array}{l}\mathrm{Hb} A_{1 c} \\
(\%)\end{array}$ & $\begin{array}{l}\text { GH } \\
(\mathrm{ng} / \mathrm{ml})\end{array}$ & $\begin{array}{l}\text { IGF BP-3 } \\
(\mu \mathrm{g} / \mathrm{ml})\end{array}$ \\
\hline $\mathrm{CH}$ & $\mathrm{F} / 22$ & 172 & $51 / 61$ & $247 / 113$ & $11.3 / 9.0$ & $2.0 / 1.2$ & $4.2 / 4.7$ \\
$\mathrm{SK}$ & $\mathrm{F} / 28$ & 170 & $65 / 73$ & $170 / 23$ & $12.0 / 7.2$ & $3.7 / 1.3$ & $3.8 / 4.2$ \\
$\mathrm{CO}$ & $\mathrm{F} / 26$ & 160 & $58 / 67$ & $401 / 103$ & $15.6 / 9.6$ & $1.5 / 1.7$ & $3.7 / 4.8$ \\
JA & $\mathrm{M} / 45$ & 185 & $62 / 72$ & $108 / 34$ & $16.8 / 8.3$ & $\mathrm{NA} / 1.2$ & $\mathrm{NA} / 3.4$
\end{tabular}

$\mathrm{HbA}_{1 \mathrm{c}}=$ glycated haemoglobin $\mathrm{A}_{1 \mathrm{c}} ; \mathrm{GH}=$ growth hormone; IGF BP-3 = insulin-like growth factor binding protein 3

Heinrich-Heine-

Düsseldorf, Germany

Correspondence to: Diabetesambulan

Heinrich-Heine-Universität 07, D-40001 Düsseldorf,

Germany.

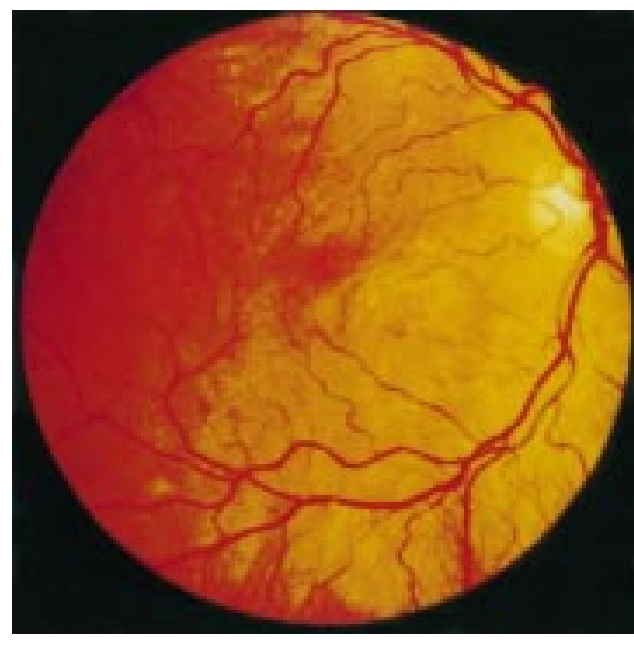

Figure 1 Fundus photograph of the right eye of patient CH. Start of improved diabetes control. Retinopathy level 1 (minimal non-proliferative retinopathy ${ }^{9}$ ); serum IGF-1 concentration $167 \mathrm{ng} / \mathrm{ml}$.

(IGF-1) dose dependently causes retinal microangiopathy in pigs, ${ }^{1}$ and neovascularisation in rabbits, ${ }^{2}$ whereas reduction of serum IGF-1 levels inhibits neovascularisation in the ischaemic mouse model. ${ }^{3}$ In human diabetic retinopathy, intravitreal growth factors (including $\mathrm{IGF}-1^{4}$ ) are elevated in relation to treatment

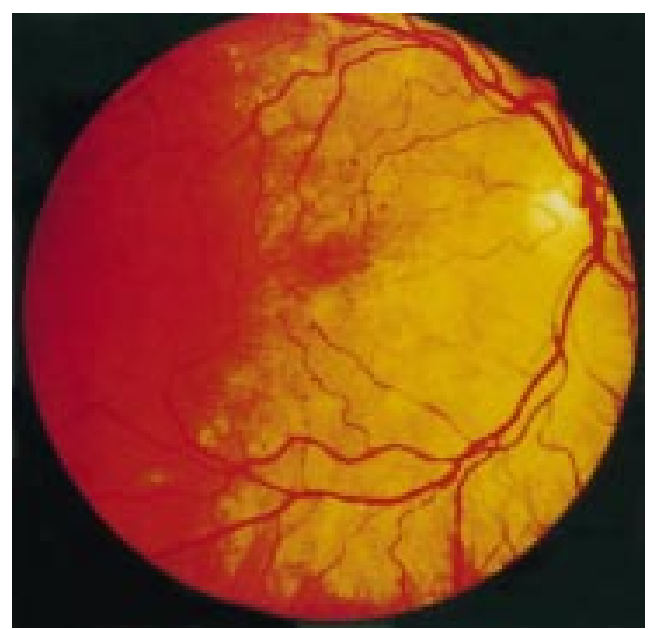

Figure 2 Fundus photograph of the right eye of patient CH 1 month after improving diabetes control. Retinopathy level 1, serum IGF-1 concentration $282 \mathrm{ng} / \mathrm{ml}$. 


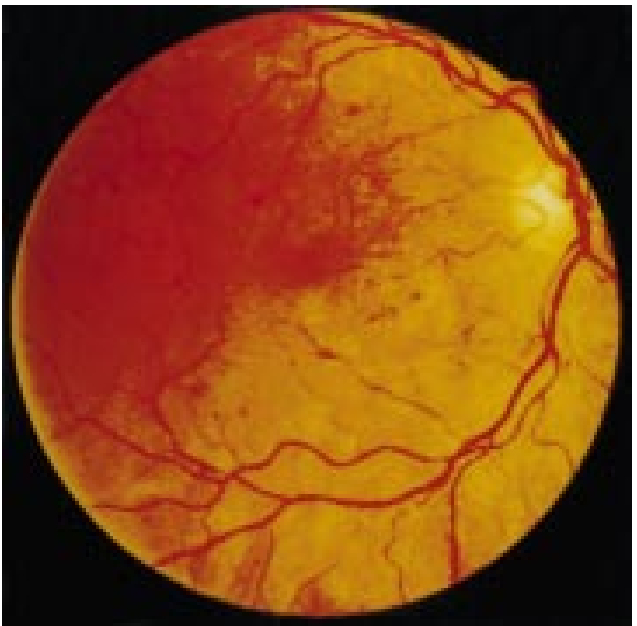

Figure 3 Fundus photograph of the right eye of patient CH 5 months after improving diabetes control. Retinopathy level 2 (moderate non-proliferative retinopathy'); serum IGF-1 level $284 \mathrm{ng} / \mathrm{ml}$.

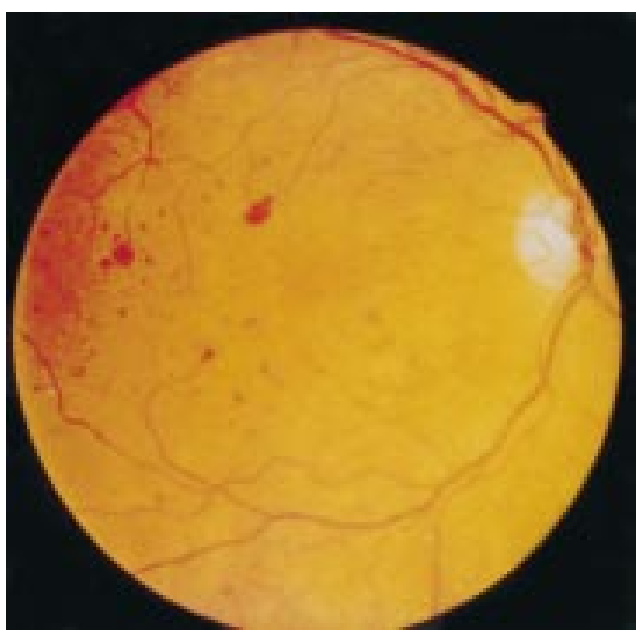

Figure 4 Fundus photograph of the right eye of patient CH 9 months after improving diabetes control. Retinopathy level 5 (proliferative retinopathy'); serum IGF-1 level 307 $n g / m l$.

with insulin. ${ }^{5}$ We have reported recently that an increase in serum IGF-1 level preceded acute progression of retinopathy in an prepubertal insulin dependent (type 1) diabetic patient, in whom chronic insulin deficiency (Mauriac's syndrome) was corrected by appropriate insulin therapy. ${ }^{6}$ In diabetes mellitus, chronic insulin deficiency decreases serum IGF-1 levels, which are upregulated again within some days after restoration of appropriate insulin therapy. ${ }^{7}$ Whether acceleration of retinopathy following IGF-1 upregulation can also be observed in type 1 diabetic patients without Mauriac's syndrome, remains to be demonstrated. The following case report describes the clinical courses of four adult patients with type 1 diabetes mellitus, in whom diabetic retinopathy deteriorated significantly following improvement of insulin therapy and upregulation of serum IGF-1 levels.

\section{Methods}

An analysis of clinical and laboratory data was obtained on four cases of sexually mature adults with type 1 (insulin dependent) diabetes
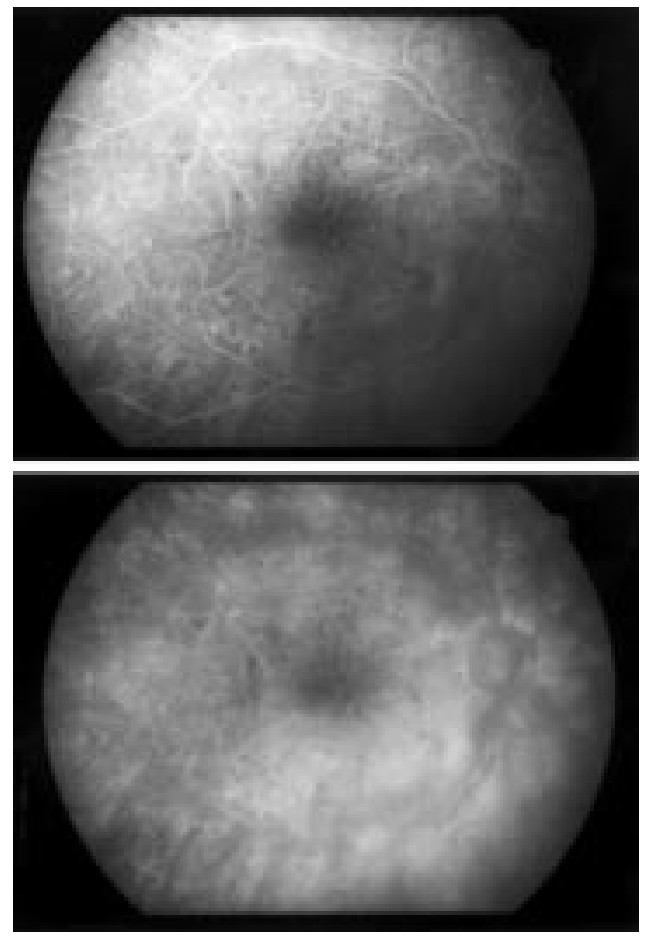

Figure 5 Fluorescein angiogram of the same eye as in Figure 3, before laser coagulation treatment.

mellitus. These patients were at risk of acceleration of diabetic retinopathy from improving glycaemic control because of the following features ${ }^{8}$ : extremely high glycated haemoglobin $\mathrm{A}_{1 \mathrm{c}}\left(\mathrm{HbA}_{1 \mathrm{c}}\right)$ for extended periods of time, incipient diabetic organ damage like neuropathy, microproteinuria, and early retinopathy, despite relatively short duration of diabetes. ${ }^{8}$ They were studied prospectively for up to 20 months before and during intensification of insulin therapy. Routine laboratory assessments were carried out including measurements of microproteinuria (by nephelometry, normal $<45 \mathrm{mg} / \mathrm{l}$ ), of plasma glucose (Beckman Glucoseanalyzer, Fullerton, USA), of $\mathrm{HbA}_{1 \mathrm{c}}$ (HPLC method, normal $<5.6 \%$ ), of serum levels of IGF-1 (IGF BP blocked radioimmunoassay, bio-Merieux, Nürtingen, Germany; assay sensitivity $0.02 \mathrm{ng} / \mathrm{ml}$ ), and of IGF BP-3 (radioimmunoassay bio-Merieux, Nürtingen, Germany, normal range 2.28-4.93 $\mu \mathrm{g} / \mathrm{ml})$. Serum growth hormone was sampled at 9.00 am and measured by immunochemiluminometry (Nicols Institute Diagnostics, San Juan Capistrano, USA). Ketonuria was assessed semiquantitatively by dipstick (Keturtest, Boehringer Mannheim, Germany). Retinopathy status was assessed by fundus photography according to the EURODIABIDDM complications study, ${ }^{9}$ and by fluorescein angiography.

\section{Patients}

There were three women and one man, whose diabetes was extremely poorly controlled for up to 3 years, owing to lack of motivation or fear of injections. Relevant clinical characteristics not mentioned in the text are summarised in Table 1. 

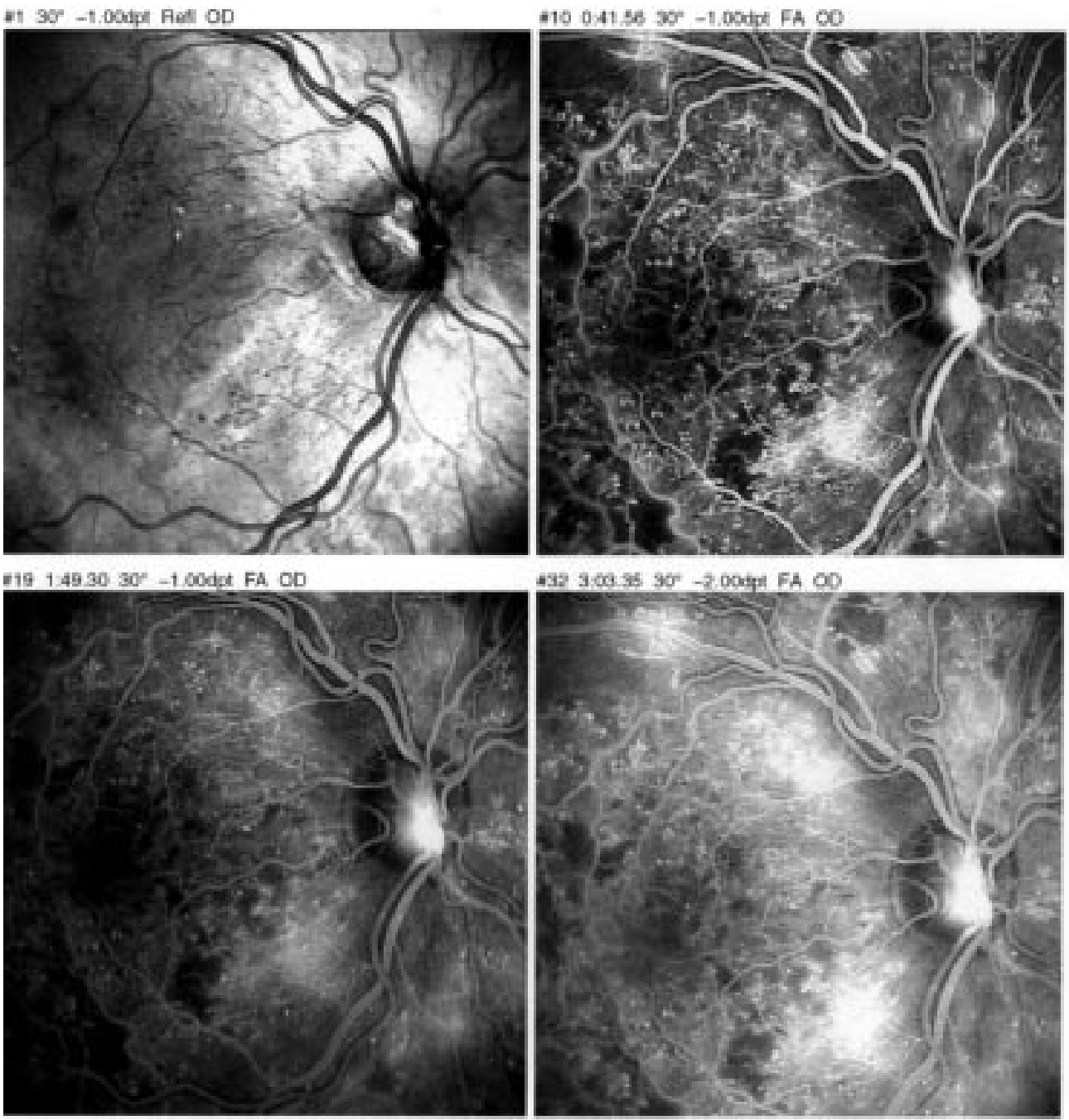

Figure 6 Fluorescein angiogram of the same eye as in Figure 4, showing new vessel on the disc.

CASE 1

$\mathrm{CH}$ was born 1974 , and was diagnosed as diabetic in 1983. She was suffering from bulimia, and was poorly controlled for several years. In October 1996 she had sought medical advice because of incipient painful neuropathy, unresponsive to intravenous infusions of $\alpha$ lipoic acid, which her family doctor had applied. On her presentation to the diabetic clinic she complained about fatigue and pain in the legs; she was under weight and amenorrhoeic. Clinical examination was normal except for hyperaesthesia of the feet. Fundus photography revealed minimal non-proliferative diabetic retinopathy (Fig 1).

CASE 2

SK was born 1968 and was diagnosed diabetic in 1986 . She had been referred to the diabetes clinic in January 1996 because of necrobiosis diabeticorum of her legs. At least during the previous 3 years, her metabolic control was very poor. During this time, she has been under weight and amenorrhoeic. On her first presentation, sensory polyneuropathy was found with reduced vibration sensation. There was extensive necrobiosis diabeticorum on both shins. Fundus photography showed minimal non-proliferative retinopathy.

\section{CASE 3}

CO was born 1971 and was diagnosed as diabetic in 1985. She had been referred in September 1997 because of amenorrhoea, neuropathic foot ulcer, and microproteinuria. She feared weight gain from appropriate insulin treatment. Fundus photography disclosed mild non-proliferative diabetic retinopathy.

CASE 4

The man (JA) was born in 1952 and was diagnosed as diabetic in 1995 (although the history of symptoms dates back to 1992). He had sought medical advice because of muscular weakness and fatigue, and increasing pains in the legs. He had lost $8 \mathrm{~kg}$ of body weight within the past year. He was under weight and showed signs of sensory neuropathy on his first presentation. Fundus photography showed minimal non-proliferative retinopathy.

\section{Results}

The clinical course during intensive insulin therapy was very similar in all four patients. It 

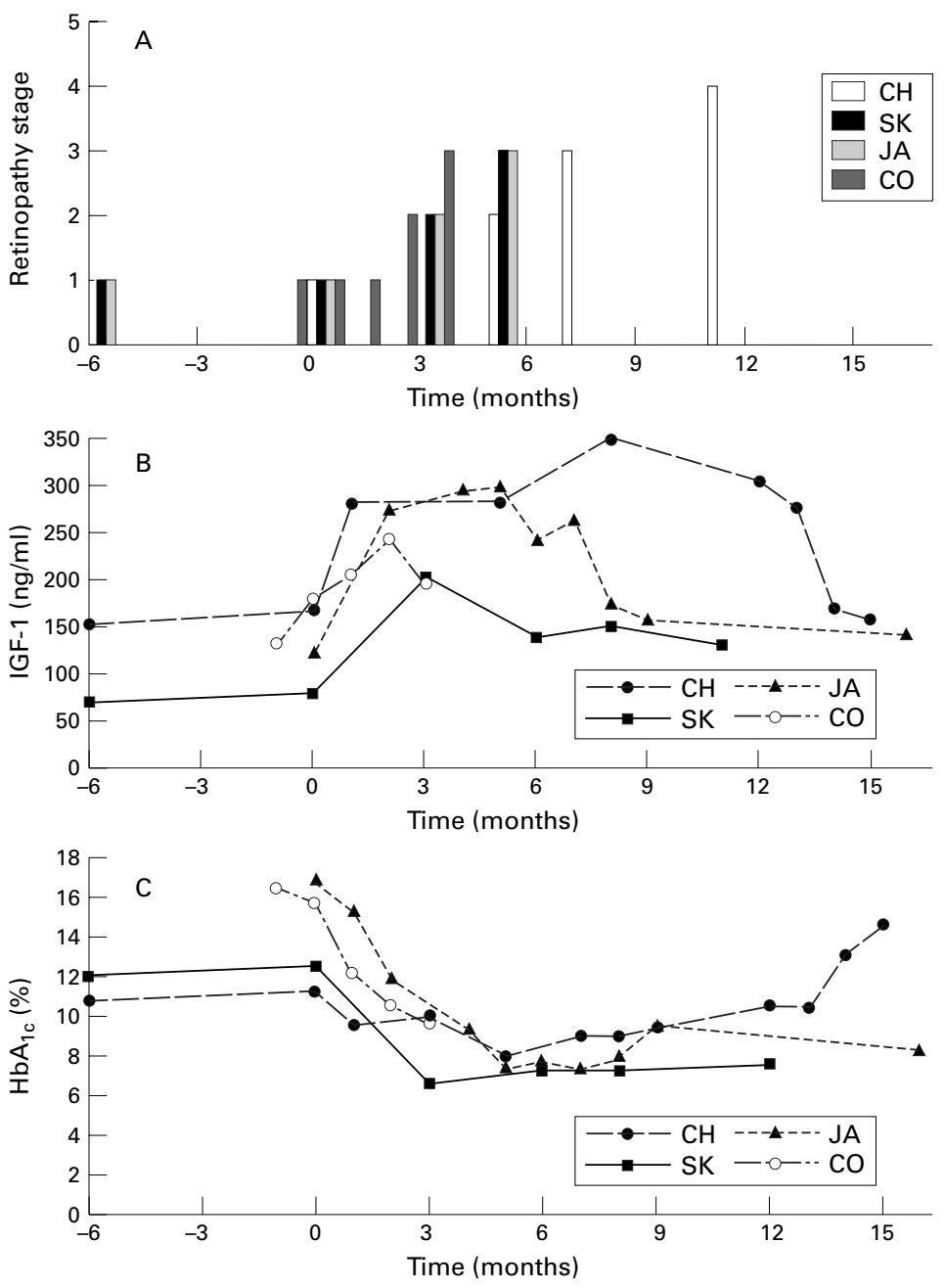

Figure 7 Dynamics of retinopathy level ${ }^{9}(A)$, serum IGF-1 (B), $H b A_{1 c}(C)$, before and after initiation of improved diabetes control (time 0) in four type 1 diabetic patients $(\mathrm{CH}$, $S K, \mathcal{F} A, C O)$. threatening macular oedema (according to fluorescein angiography). Initially, serum IGF-1 levels increased in all patients from low normal to high normal levels. ${ }^{10}$ After some months with the $\mathrm{HbA}_{1 \mathrm{c}}$ level around $8 \%-10 \%$ (corresponding to an average glycaemia of $10-14 \mathrm{mmol} / \mathrm{l}$ ), serum IGF-1 levels declined in three patients (Fig 7).

In patient $\mathrm{CH}$ IGF-1 levels did not decline, while macular oedema persisted with reduction in visual acuity to 0.4 . Laser coagulation treatment was suspended. Only after the insulin dosage was reduced in order to lower her IGF-1 level to $160 \mathrm{ng} / \mathrm{ml}$, did macular oedema resolve, and she regained full visual acuity. Laser treatment was continued.

Growth hormone levels were in the normal range before, and decreased within the normal range after improving diabetes control; serum levels of IGF BP-3 behaved accordingly (Table 1). After 7 to 16 months, proteinuria had normalised in two, and symptomatic neuropathy had disappeared in all patients. All of them had regained normal body weight (Table 1 ) without clinical evidence of oedema, and the women reported regular menstrual bleeding.

\section{Discussion}

The present longitudinal data extend previous observations on a role of elevated serum IGF-1 in accelerating human diabetic retinopathy, ${ }^{411} 12$ which cross sectional studies ${ }^{13}{ }^{14}$ were unable to disclose. In all four cases, the institution of sufficient insulin substitution induced an overshooting upregulation of serum IGF-1 within some weeks, which $2-8$ weeks later was followed by a significant progression of early diabetic retinopathy to a sight threatening stage with macular oedema. One patient with severe macular oedema was re-exposed to insulin deficiency; while glycaemia and $\mathrm{HbA}_{1 \mathrm{c}}$ levels increased serum IGF-1 decreased and the macular oedema improved. Paradoxical worsening of pre-existing diabetic retinopathy after improved diabetes control (by intensive insulin therapy) had been noted repeatedly, and termed "normoglycaemic re-entry phenomenon". ${ }^{15-20}$ Most recently, this phenomenon was observed in the secondary intervention cohort of the DCCT. ${ }^{21}$ The present data may help to explain it. A decreased hepatic IGF-1 production in the presence of elevated growth hormone secretion $^{10}$ is a less well known consequence of chronic insulin deficiency; another consequence is hyperglycaemia. Adequate insulin substitution to improve glycaemic control reverses this abnormality by upregulating IGF-1. The present data show that, if the increase in serum IGF-1 is large enough and the retina is already sufficiently damaged from hypoxia, this IGF-1 upregulation is followed by acute progression of retinopathy. The progression started with severe oedematous changes. A cause-effect relation is highly likely, since serum and vitreous IGF-1 concentrations are positively correlated (at least in proliferative diabetic retinopathy ${ }^{4}$ ), owing to leaking of IGF-1 from the bloodstream. ${ }^{22}$ Furthermore, adverse effects on the normal ${ }^{23}$ 
and the diabetic retina ${ }^{24}$ have been reported with systemic application of recombinant human IGF-1. The exact mechanism by which IGF-1 exerts its action on the retina is still unknown. Possibly, IGF-1 acts as a mediator to other factors that may be involved, such as the rate of fall of blood glucose, ${ }^{25}$ other growth factors ${ }^{42}$-for example, vascular endothelial growth factor (VEGF), the local production of which is increased by chronic retinal hypoxia. ${ }^{27}$ Hypoxia also increases retinal IGF-1 production. ${ }^{28}$ Thus, increased serum IGF-1 would enhance its local effects by adding to its local concentrations, and/or enhance hypoxia induced VEGF activity, ${ }^{27}{ }^{29}$ thereby accelerating diabetic retinopathy. Serum VEGF, although positively correlated with $\mathrm{HbA}_{1 \mathrm{c}}{ }^{30}$ is unrelated to vitreous VEGF. ${ }^{31}$

The hypothesis that serum IGF-1 can accelerate diabetic retinopathy may also work in physiological conditions with elevation of serum IGF-1, like puberty and pregnancy, both of which carry an increased risk of progression of diabetic retinopathy. ${ }^{32-35}$ It further explains why pituitary ablation (substantially reducing growth hormone and IGF- $1^{10}$ ) acutely improved visual acuity in some cases of diabetic retinopathy, ${ }^{36}$ and invariably stopped proliferative diabetic retinopathy. ${ }^{37}$

In summary, the present data show that an increase in serum IGF-1 levels by $70-220 \%$ subsequent to improving diabetes control was followed by severe deterioration of diabetic retinopathy in four type 1 diabetic patients with early diabetic microangiopathy. In one patient, re-exposure to poor diabetes control lowered serum IGF-1 and resolved macular oedema consistent with a previous report. ${ }^{38}$ In consideration of the established adverse effects of exogenous IGF-1 on the diabetic microcirculation, and the benefit of pituitary ablation on proliferative diabetic retinopathy, a causal effect of the increased serum IGF-1 is highly probable. These data are preliminary and need further studies before firm recommendations with respect to treatment can be given-for example, watchful waiting, ${ }^{39}$ suppression of IGF-1 with a somatostatin analogue, ${ }^{3}$ temporary restoration of former insulin deficiency, or early preventive laser coagulation. ${ }^{15}$ However, the present cases suggest that the "normoglycaemic re-entry phenomenon" should be regarded as another particular risk factor for the progression of diabetic retinopathy, like cataract surgery or diabetic nephropathy.

Presented in parts at the annual meeting of the European Association for the Study of Diabetes (EASD) in Helsinki 1997, and at the Joint EASD/Juvenile Diabetes Foundation Meeting in Oxford, 1997.

The cooperation of Dr K Lemmen, PhD, director of the Eye Clinic at the St Martinus-Krankenhaus in Düsseldorf is gratefully acknowledged. I am also indebted to the staff of the diabetic outpatient clinic-namely, Drs S Bott and G Neises, and Mrs S Scholz, and to Dr Feldkamp and his endocrinology laboratory staff.

1 Danis RP, Bingaman DP. Insulin-like growth factor-1 retinal microangiopathy in the pig eye. Ophthalmology 1997; 104:1661-9.

2 Grant MB, Mames RN, Fitzgerald C, et al. Insulin-like growth factor-1 acts as an angiogenic agent in rabbit
cornea and retina: comparative studies with basic fibroblast cornea and retina: comparative studies with
growth factor. Diabetologia 1993;36:282-91.
3 Smith LEH, Kopchick JJ, Chen W, et al. Essential role of growth hormone in ischaemia induced retinal neovascularigrowth hormone in ischaemia ind

4 Grant M, Russell B, Fitzgerald C, et al. Insulin-like growth factors in vitreous. Diabetes 1986;35:416-20

5 Boulton M, Gregor Z, McLeod D, et al. Intravitreal growth factors in proliferative diabetic retinopathy: correlation with neovascular activity and glycaemic management. $\mathrm{Br} \mathcal{F}$ Ophthalmol 1997;81:228-33.

6 Chantelau E, Eggert H, Seppel T, et al. Elevation of serum GF-1 precedes proliferative diabetic retinopathy in Mauriac's syndrome. Br F Ophthalmol 1997;81:169-70.

7 Glaser EW, Goldstein S, Phillips LS. Nutrition and somatomedin. Diabetes 1987;36:1152-60.

8 Moskalets E, Galstyan G, Starostina E, et al. Association of blindness to intensification of glycemic control in insulindependent diabetes mellitus. F Diab Comp 1994;8:45-50.

9 Aldington SJ, Kohner EM, Meurer S, et al for the Aldington SJ, Kohner EM, Meurer S, et al for the
EURODIAB-IDDM Complications Study Group. Methodology for retinal photography and assessment of Methodology for retinal photography and assessment of tions Study. Diabetologia 1995;38:437-44.

10 LeRoith D. Insulin-like growth factors. N Engl f Med 1997; 336:633-40

11 Merimee TJ, Zapf J, Froesch ER. Insulin-like growth actors: studies in diabetics with and without retinopathy. N Engl f Med 1983;309:527-30.

12 Hyer SL, Sharp PS, Sleightholm M, et al. Progression of diabetic retinopathy and changes in serum insulin-like growth factor 1(IGF-1) during continuous subcutaneous insulin infusion (CSII). Horm Metabol Res 1989;21:18-22.

13 Dills DG, Moss SE, Klein R, et al. Is insulin-like growth factor 1 associated with diabetic retinopathy? Diabetes 1990;39:191-5.

14 Wang Q, Dills DG, Klein R, et al. Does insulin-like growth factor 1 predict incidence and progression of diabetic retinopathy? Diabetes 1995;44:161-4.

15 Chantelau E, Kohner EM. Why some cases of retinopathy worsen when diabetic control improves. BMF 1997;315: $1105-6$

16 Kingsley R, Ghosh G, Lawson P, et al. Severe diabetic retinopathy in adolescents. Br F Ophthalmol 1983;67:73-89.

17 Dahl-Jorgensen K, Brinchmann-Hansen O, Hanssen KF, et al for Diabetes Group. Rapid tightening of blood glucose control leads to transient deterioration of diabetic retinopathy in insulin-dependent diabetes mellitus: the Oslo Study. BMF 1985;290:811-15.

18 Kroc Collaborative Study Group. Diabetic retinopathy after 2 years of intensified insulin treatment. $\mathcal{F} A M A$ 1988;260: $37-41$.

19 Carroll PB, Herskowitz RD, Goodman AD, et al. Rapid onset of severe retinopathy, cataracts and neuropathy in

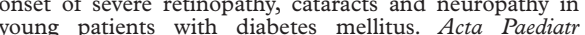
young patien

20 Agardh CD, Eckert B, Agardh E. Irreversible progression of severe retinopathy in young type-1 insulin-dependent diabetes mellitus after improved metabolic control. F Diab Comp 1992;6:96-100.

21 Diabetes Control and Complications Trial Research Group. The effect of intensive treatment of diabetes on the development and progression of long-term complications in insulin-dependent diabetes mellitus. $N$ Engl $7 \mathrm{Med}$ 1993;329:977-86.

22 Spranger J, Bühnen J, Meyer-Schwickerath R, et al. Anstieg von IGF-1, IGF-2 und IGFBP-3 im menschlichen Glaskörper als Konsequenz einer Blut-RetinaSchrankenstörung bei Paienten mit proliferativer diabetischer Retinopathie. (Abstract.) Diab Stoffw 1998; 7(Suppl 1):32.

23 Hussain MA, Studer K, Messmer EP, et al. Treatment with insulin-like growth factor I alters capillary permeability in skin and retina. Diabetes 1995;44:1209-12.

$24 \mathrm{Genentech/Roche} \mathrm{Inc.} \mathrm{IGF-1} \mathrm{in} \mathrm{diabetes.} \mathrm{Clinical} \mathrm{back-}$ ground brochure. London, 1996.

$25 \mathrm{Li}$ W, Liu X, Yanoff M, et al. Cultured retinal capillary pericytes die by apoptosis after an abrupt fluctuation from high to low glucose levels: a comparative study with retinal capillary endithelial cells. Diabetologia 1996;39:537-47.

26 Schlingemannn RO, van Hinsbergh VWM. Role of vascular permeability factor/vascular endothelial growth factor on eye disease. Br $\mathcal{F}$ Ophthalmol 1997;81:501-12.

27 Aiello LP, Northrup KM, Keyt BA, et al. Hypoxic regulation of vascular endothelial growth factor in retinal cells. Arch Ophthalmol 1995;113:1538-44.

28 Averbukh EA, Weiss O, Yanko R, et al. IGF system gene expression in hypoxic retina. (abstract) Diabetologia 1997; 40(Suppl 1):A 493.

29 Punglia RS, Lu M, Hsu J, et al. Regulation of vascular endothelial growth factor expression by insulin-like growth factor 1. Diabetes 1997;46:1619-26.

30 Al-Mrayat M, Sharp P, Chong P. Circulating vascular endithelial growth factor in diabetic patients. (abstract) Diabetic Med 1997;14(Suppl 4):S 39

31 Burgos R, Simo R, Audi L, et al. Vitreous levels of vascular endothelial growth factor are not influenced by its serum concentrations in diabetic retinopathy. Diabetologia 1997; 40:1107-9.

32 Bhaumick B, Danilkewich AD, Bala RM. Insulin-like growth factors (IGF) I and II in diabetic pregnancy: suppression of normal pregnancy-induced rise of IGF-I. Diabetologia 1986;29:792-7.

33 Roger D,Sherman LD, Gabbay KH. Effect of puberty on insulin-like growth factor I and HbA1 in type-1 diabetes. Diabetes Care 1991;14:1031-5. 
34 Klein BEK, Moss SE, Klein R. Is menarche associated with diabetic retinopathy? Diabetes Care 1990;13:1034-8.

35 Chew EY, Mills JL Metzger BE, et al. Metabolic control and progression of retinopathy. The Diabetes in Early Pregnancy Study. Diabetes Care 1995;18:631-7.

36 Lundbaek K, Jensen VA, Olsen TS, et al. Diabetes, diabetic angiopathy, and growth hormone. Lancet 1970;ii:131-3.

37 Sharp PS, Fallon TJ, Brazier OJ, et al. Long-term follow-up of patients who underwent yttrium-90 pituitary implanta- tion or treatment of proliferative diabetic retinopathy. Diabetologia 1987;30:199-207.

38 Shigetou M, Sagawa T, Ishibashi T, et al. Exacerbation of diabetic retinopathy following systemic insulin-like growth factor-1. Ipn f Clin Ophthalmol 1997;51:1251-5.

39 Rosenlund EF, Haakens K, Brinchmann-Hansen O, et al

Transient proliferative diabetic retinopathy during insulin treatment. Am f Ophthalmol 1988;105:618-25. 